\title{
A general equilibrium model of trilateral trade with oil duopoly
}

\author{
Koo Woong Park ${ }^{*}$
}

\begin{abstract}
I study the economic implications of the world oil market dominated by OPEC and non-OPEC major oil producing countries using a general equilibrium model of trilateral trade with oil duopoly. There are three countries and three goods, $x, y$, and oil (z). Home (H) is endowed with good $x$. Foreign $(F)$ is endowed with good $y$ and also produces oil (z). Middle (M) is an oil producing country and supplies oil only. I consider two types of oil market structure; (1) Cournot duopoly and (2) perfect competition. I find that Foreign is actually worse off under Cournot duopoly despite being a duopolist for wide range of parameter values that reflect real world situations. This is mainly due to reduced consumption of oil and reduced value of good y endowment under duopoly when Foreign is a net oil exporter or oil autarky, and is also due to worsening terms-of-trade effect under duopoly when Foreign is a net oil importer. Welfare reversal with higher welfare of Foreign under oil duopoly occurs only under highly unrealistic parameter values, and hence the main results of the study remain robust.
\end{abstract}

Keywords: Cournot duopoly, net oil importer, net oil exporter, welfare reversal, terms-of-trade effect.

\section{Introduction}

The world oil market is dominated by two groups of countries. One is OPEC (Organization of the Petroleum Exporting Countries) ${ }^{1}$ and the other is non-OPEC major oil producing countries such as Russia, US, Mexico, Norway, and China. Eleven OPEC member countries supplied 38.4\%

\footnotetext{
Submission Date: 12/12/2007

Revision Date: 19/11/2008

Acceptance Date: 10/12/2008

*Corresponding Author, BK21, Department of Economics Seoul National University 599 Gwanak-ro, Gwanak-gu, Seoul, 151-742, Korea, Telephone: 02-880-4061 Mobile: 010-7900-0372 Fax: 02-872-7297 E-mail: kwpark@snu.ac.kr

${ }^{1}$ There were 11 member countries in OPEC in 2002. They are Iran, Iraq, Kuwait, Qatar, Saudi Arabia, United Arab Emirates, Algeria, Libya, Nigeria, Indonesia, and Venezuela.
} 
and consumed $6.6 \%$ (except Iraq, Libya, and Nigeria for which no data is available) of the world oil supply in year 2002. ${ }^{2}$ The 5 countries of the second group supplied $34.8 \%$ and consumed $38.5 \%$ in the same year. The most striking fact from this data is that all of 11 OPEC countries are net exporters (average production/consumption ratio $=4.70$ excluding Iraq, Libya, and Nigeria) of oil by a huge margin. The 5 non-OPEC oil producing countries as a group are net importers (average production/consumption ratio $=0.90$ ), albeit there is a large variance among these countries. Russia, Mexico, and Norway are net exporters (production/consumption ratio $=3.12$ for Russia and 2.00 for Mexico), but US and China are net importers (production/consumption ratio = 0.39 for US and 0.63 for China) of oil. Secondly, oil production accounts for an absolute major share in GDP for OPEC member countries, but it has only a small fraction for the 5 non-OPEC oil producing countries. Apart from these two groups, there is a third group of countries, typically industrialized, such as France, Germany, Italy, Japan, and South Korea, which do not produce oil at all (only Italy produced $0.2 \%$ of world oil supply in 2002) but consume a large amount of oil (18.7\% of world oil in 2002). They rely almost $100 \%$ on imports for their oil consumption. These three groups of countries accounted for $73.4 \%$ of supply and $63.8 \%$ of consumption in the world oil market in 2002. To get a glimpse of the impact of this oil market structure on the world economy, we compare the share of GDPs of these groups. 11 OPEC countries' share of GDP in the world economy was $2.5 \%$, the 5 non-OPEC oil producing countries' share $39.5 \%$, and the last 5 non-oil producing countries' share $28.6 \%$ in 2001 . $^{3}$ Total oil's share in the world economy was about $2.2 \%$ in $2001 .^{4}$ We can see here that oil's share in the world GDP is small but we know from the past events that oil price fluctuations have a far-reaching effect on the world economy.

This market structure has distinctive features. First of all, the world oil market is quite close to a duopoly ${ }^{5}$ with highly asymmetric supply-demand structure. Secondly, there is clearly an important third player in the oil market, i.e. the non-oil producing industrialized countries. None of these three groups are negligible in the world oil market. We analyse this particular market structure and study the equilibrium and welfare implications in a general equilibrium model of trilateral trade with Cournot duopoly in oil supply. We have three countries, Home $(H)$, Foreign $(F)$, and Middle $(M)$, and three goods, $x, y$, and oil $(z)$. Home is endowed with good $x$. Foreign is endowed with good $y$ and also produces oil $(z)$. Middle is an oil producing country and supplies oil only. Oil is produced with a linear technology using a single input of labour. We assume an endowment economy for good $x$ and $y$ to concentrate on the effects of the oil duopoly. Home agents have a Cobb-Douglas utility function of the three goods. Foreign and Middle agents have an additively separable utility function of three goods in Cobb-Douglas form and leisure in

\footnotetext{
${ }^{2}$ BP Statistical Review of World Energy, June 2003.

${ }^{3}$ National Accounts Statistics: Analysis of Main Aggregates, 2001, New York, United Nations, 2003

${ }^{4}$ This is calculated indirectly using GDP data from National Accounts Statistics, Table 1.A, United Nations, 2003 and oil production data from BP Statistical Review of World Energy, June 2003. The latter does not have the direct data on oil production in dollar terms. We multiply oil production per day by 365 days and Brent oil price per barrel in 2001 to estimate the oil production per year in dollar terms. World GDP was USD 31,041,300 million at current price. Oil production was 74,350 thousand barrels per day and Brent crude oil spot price was USD 24.77 per barrel in 2001, respectively. This estimation is obviously not precise, but the error would not be dramatic either.

${ }^{5}$ The second group of oil producing countries do not coordinate as closely as OPEC countries, but they do discuss about how to deal with the global oil supply in the time of prospective oil crisis.
} 
logarithmic form. As these preferences will lead to non-linear demand functions and hence will have income effects on the monopolistic sector (oil, $z$ ), we adopt general equilibrium analysis rather than partial equilibrium analysis in our model. We consider two types of oil market structure. First, in Cournot duopoly, Foreign and Middle set their oil supply (consequently, oil price) simultaneously in the world oil market. Second, under perfect competition, Foreign and Middle supply oil competitively.

Most of the present papers focus on two-country symmetric model. Lucas (1982) develops a model of a general two-good/two-country exchange economy with endowment. He covers both pure barter economy and monetary economy under fixed and floating exchange rate regimes. The main difference of his model from ours is the inclusion of money and equity trading. This equity trading in perfectly symmetric two-country model enables perfect risk sharing between the two countries at all time given identical initial equity holdings. Singh and Vives (1984) analyse the optimal choice of a strategic variable in a two stage game where two firms first choose the type of contract, either quantity contract or price contract, and afterwards they compete contingent on the chosen types of contracts. Each firm produces a single differentiated good. Singh and Vives find that firms choose the quantity (price) as the dominant strategy when the two goods are substitutes (complements) and they have only two strategies \{quantity contract, price contract\}. That is, Cournot (Bertrand) duopoly will obtain endogenously when two goods are substitutes (complements). They show that this result holds not only for a linear demand function but also for a non-linear demand function. Lambertini (1997) studies the choice between quantity and price in order to stabilize collusion between two firms each with a single product. Lambertini extends Singh and Vives (1984) in the sense that he also considers the mixed situation where two firms optimize in different variables, i.e. one firm in quantity and the other in price. Lambertini (1997, 183-189) finds, for a two stage game where firms choose the strategic variable in the first stage and then optimize production in the second stage given the chosen variable, that firms choose the quantity as the strategic variable in a single period game like in Singh and Vives but choose price in a repeated game. However, when firms choose both the variable and behaviour, cooperative or noncooperative, at the same time, Lambertini (1997, 189-190) finds that firms will choose quantity as their strategic variable and behave non-cooperatively. Dowrick (1986) studies the endogenous choice of roles, either leader or follower, in a duopoly and shows that Stackelberg equilibrium is preferred to Cournot equilibrium irrespective of the slopes of the reaction functions. Dowrick suggests that Cournot equilibrium may be chosen only as a compromise or collusive solution. Rees (1993) analyses the collusion in setting prices in the white salt duopoly case in the UK for the relatively short period of 1980 to 1984 . "Salt production in the United Kingdom consists essentially of the extraction and processing of a non-renewable natural resource. However, reserves are so large ... we can regard salt as a manufactured commodity." We may treat oil in our model as a manufactured commodity as well in this sense. Nero (1996) analyses a structural model of intra European Union duopoly airline competition with two countries and two airlines. Two main assumptions of Nero are returns to density effect and hub-and-spoke (HS) network structure. Cox and Walker (1998) carry out very intuitive experiments on learning to play Cournot duopoly

\footnotetext{
${ }^{6}$ R. Rees(1993), Collusive equilibrium in the Great salt duoply. Economic Journal. 103, 837.
} 
strategies for two types of reaction curves; Type I - normal stable interior equilibrium case and Type II - case with one unstable interior equilibrium and two stable boundary equilibria with very rapidly decreasing marginal costs. Cox and Walker $(1998,144)$ find in their experiments convergence to a stable interior equilibrium for Type I, but no convergence to any equilibrium in a Type II duopoly. Hence, their experimental results are consistent with the theory in the usual stable interior equilibrium case but not in the uncommon stable boundary equilibria case.

When two differentiated goods are substitutes (complements) in a duopoly, the dominant strategy variable for each firm is quantity (price) because Cournot competition is more monopolistic with higher price and lower quantity than Bertrand competition. (Singh and Vives, 1984, 549; Lambertini, 1997, 181-182) In our model the two goods are identical, i.e. perfect substitutes which is oil, $z$. Lambertini $(1997,190)$ also shows that quantity is a dominant strategic variable to price even in repeated games in the non-cooperative set-up. Hence, I study Cournot competition in my oil duopoly model rather than Bertrand competition.

The rest of the paper comprises as follows. Section 2 outlines the structure of the base Cournot duopoly model and solves the representative agent's optimization problem. In section 3, I derive the equilibrium of the base Cournot duopoly model. In section 4, I apply the base model of sections 2 and 3 to the competitive oil supply case. section 5 studies the equilibrium welfare using numerical data. I adopt a non-linear approach rather than linear approximations, using specific parameter and exogenous variable values. I compare oil supply, consumption, and welfare between Cournot duopoly and perfect competition. I also run a simulation for wide range of parameter /exogenous variable values and confirm the main results. Section 6 concludes.

\section{Cournot oil duopoly}

There are three countries; Home $(H)$, Foreign $(F)$, and Middle $(M)$. 'Home' stands for nonoil producing industrialized countries. 'Foreign' stands for non-OPEC oil producing industrialized countries. Foreign is assumed to be net oil importer. 'Middle' stands for OPEC countries as net oil exporters. There are three goods; good $x, \operatorname{good} y$, and $z$ (oil). The representative agent of the Home country is endowed with $\bar{x}$ units of good $x$, whereas the representative agent of the Foreign country is endowed with $\bar{y}$ units of good $y$. The third good, oil, requires labour to produce it. Only the Foreign and Middle country can produce oil. Good $x$ is used as a numeraire and its price is normalized to $p_{x}=1$. Good $y$ price, $p_{y}$, and oil price, $p_{z}$, are expressed in good $x$ units. The population of each country is normalized to one. We consider here 1-period model only. Without capital accumulation, this will have qualitatively the same results as multi-period or infinite period models.

\subsection{Oil producer's problem}

The amount of oil produced in the Foreign and Middle is assumed to be a linear function of the labour used in production, i.e. 


$$
Z^{k}=A l^{k}
$$

$k=F, M$, and $\mathrm{Z}^{k}$ is the amount of oil produced by the $k$ oil monopolist. Productivity factor $A$ is assumed to be constant. Each Foreign and Middle agents are endowed with one unit of labour which they can use either for oil production or for leisure. Each oil monopolist has a monopsony power in recruiting labour within its own country and a duopoly power in the world oil market. Labour market comprises a single oil monopolist as an employer and a continuum of identical consumer agents who supply labour competitively. We assume labour immobility internationally, e.g. Foreign oil monopolist can hire only Foreign labour.

The Foreign oil monopolist maximizes its profit from oil production as follows.

$$
\max _{l_{i}^{F}} \Pi^{F}=p_{z} Z^{F}-w^{F} \int_{0}^{1} l_{i}^{F} d i=p_{z} A \int_{0}^{1} l_{i}^{F} d i-w^{F} \int_{0}^{1} l_{i}^{F} d i
$$

where $l_{i}^{F}$ is the amount of labour demand of the $i^{\text {th }}$ Foreign agent. The labour wage rate in Foreign country's oil production sector is $w^{F}$ in good $x$ units.

The Foreign oil monopolist's first order condition over its labour demand is given as follows.

$$
p_{z} A+\frac{\partial p_{z}}{\partial l_{i}^{F}} A \int_{0}^{1} l_{i}^{F} d i-w^{F}-\frac{\partial w^{F}}{\partial l_{i}^{F}} \int_{0}^{1} l_{i}^{F} d i=0
$$

With perfectly symmetric agents, we must have at equilibrium, $l_{i}^{F}=l^{F}$ for all $i \in[0,1]$, and we can drop the individual index subscript $i$ in the above Euler equation. Hence, we get

$$
p_{z} A+\frac{\partial p_{z}}{\partial l^{F}} A l^{F}-w^{F}-\frac{\partial w^{F}}{\partial l^{F}} l^{F}=0 \quad\left(\mathrm{E} . \mathrm{O}^{\mathrm{F}}\right) \text { and } \Pi^{F}=\left(p_{z} A-w^{F}\right) l^{F}
$$

Similarly, the Middle oil monopolist maximizes its profit from oil production as follows.

$$
\max _{l_{i}^{M}} \Pi^{M}=p_{z} Z^{M}-w^{M} \int_{0}^{1} l_{i}^{M} d i=p_{z} A \int_{0}^{1} l_{i}^{M} d i-w^{M} \int_{0}^{1} l_{i}^{M} d i
$$

where $\mathrm{Z}^{M}$ is the amount of oil produced by the Middle oil monopolist and $l_{i}^{M}$ is the amount of labour demand of the $i^{\text {th }}$ Middle agent.

Optimizing over $l_{i}^{M}$, we get the following Euler equation for the Middle oil monopolist. 


$$
p_{z} A+\frac{\partial p_{z}}{\partial l^{M}} A l^{M}-w^{M}-\frac{\partial w^{M}}{\partial l^{M}} l^{M}=0 \quad\left(\mathrm{E} . \mathrm{O}^{\mathrm{M}}\right) \text { and } \Pi^{M}=\left(p_{z} A-w^{M}\right) l^{M}
$$

\subsection{Representative agent's problem}

A representative $i^{\text {th }}$ Home consumer agent maximizes his utility.

$$
\max _{\left\{x_{i}^{H}, y_{i}^{H}, z_{i}^{H}\right\}} u_{i}^{H}=\left(x_{i}^{H}\right)^{\alpha}\left(y_{i}^{H}\right)^{\gamma}\left(z_{i}^{H}\right)^{1-\alpha-\gamma}, \quad \alpha, \gamma, \alpha+\gamma \in(0,1)
$$

subject to the budget constraint $x_{i}^{H}+p_{y} y_{i}^{H}+p_{z} z_{i}^{H} \leq s_{i}^{x} \bar{x}$ where $x_{i}^{H}, y_{i}^{H}$, and $z_{i}^{H}$ are the $i^{\text {th }}$ Home consumer agent's demand for good $x, y$, and oil, respectively, and $s_{i}^{x}$ is his share of good $x$ endowment.

The representative agent of the Home country is a price taker in all markets and therefore using standard maximization subject to the budget constraint implies

$$
\begin{aligned}
& \frac{\partial u_{i}^{H}}{\partial x_{i}^{H}}=\alpha\left(x_{i}^{H}\right)^{\alpha-1}\left(y_{i}^{H}\right)^{\gamma}\left(z_{i}^{H}\right)^{1-\alpha-\gamma}=\lambda_{i}^{H} \\
& \frac{\partial u_{i}^{H}}{\partial y_{i}^{H}}=\gamma\left(x_{i}^{H}\right)^{\alpha}\left(y_{i}^{H}\right)^{\gamma-1}\left(z_{i}^{H}\right)^{1-\alpha-\gamma}=\lambda_{i}^{H} p_{y} \\
& \frac{\partial u_{i}^{H}}{\partial z_{i}^{H}}=(1-\alpha-\gamma)\left(x_{i}^{H}\right)^{\alpha}\left(y_{i}^{H}\right)^{\gamma}\left(z_{i}^{H}\right)^{-\alpha-\gamma}=\lambda_{i}^{H} p_{z} \\
& x_{i}^{H}+p_{y} y_{i}^{H}+p_{z} z_{i}^{H}=s_{i}^{x} \bar{x}
\end{aligned}
$$

where $\lambda_{i}^{H}$ is the Lagrangian multiplier associated with this problem.

Similarly, a representative $i^{\text {th }}$ Foreign consumer agent maximizes his utility.

$$
\max _{\left\{x_{i}^{F}, y_{i}^{F}, z_{i}^{F}, l_{i}^{F}\right\}} u_{i}^{F}=\left(x_{i}^{F}\right)^{\alpha}\left(y_{i}^{F}\right)^{\gamma}\left(z_{i}^{F}\right)^{1-\alpha-\gamma}+\kappa \log \left(1-l_{i}^{F}\right), \quad 0 \leq l_{i}^{F} \leq 1
$$

subject to the budget constraint $x_{i}^{F}+p_{y} y_{i}^{F}+p_{z} z_{i}^{F} \leq p_{y} s_{i}^{y} \bar{y}+w^{F} l_{i}^{F}+s_{i}^{F} \Pi^{F}$ in good $x$

\footnotetext{
${ }^{7}$ We can add a leisure term, $k \log \left(1-l^{H}\right)$ in the Home agents' utility function, where $l^{H}$ is Home agents' labour supply in oil production. However, this does not make any difference because Home agents do not supply any labour in oil production and hence that utility term becomes zero for $H^{H}=0$. cf. Equations (7) and (8) below.
} 
units. The parameter $\kappa$ represents the weight on the leisure relative to goods consumption in utility.

Solving the first order conditions of this problem subject to budget constraint, we get the following results.

$$
\begin{aligned}
& \frac{\partial u_{i}^{F}}{\partial x_{i}^{F}}=\alpha\left(x_{i}^{F}\right)^{\alpha-1}\left(y_{i}^{F}\right)^{\gamma}\left(z_{i}^{F}\right)^{1-\alpha-\gamma}=\lambda_{i}^{F} \\
& \frac{\partial u_{i}^{F}}{\partial y_{i}^{F}}=\gamma\left(x_{i}^{F}\right)^{\alpha}\left(y_{i}^{F}\right)^{-1}\left(z_{i}^{F}\right)^{1-\alpha-\gamma}=\lambda_{i}^{F} p_{y} \\
& \frac{\partial u_{i}^{F}}{\partial z_{i}^{F}}=(1-\alpha-\gamma)\left(x_{i}^{F}\right)^{\alpha}\left(y_{i}^{F}\right)^{\gamma}\left(z_{i}^{F}\right)^{-\alpha-\gamma}=\lambda_{i}^{F} p_{z} \\
& -\frac{\kappa}{1-l_{i}^{F}}+\lambda_{i}^{F} w^{F}=0 \\
& x_{i}^{F}+p_{y} y_{i}^{F}+p_{z} z_{i}^{F}=p_{y} s_{i}^{y} \bar{y}+w^{F} l_{i}^{F}+s_{i}^{F} \Pi^{F}
\end{aligned}
$$

Finally, a representative $i^{\text {th }}$ Middle agent maximizes his utility.

$$
\max _{\left\{x_{i}^{M}, y_{i}^{M}, z_{i}^{M}, l_{i}^{M}\right\}} u_{i}^{M}=\left(x_{i}^{M}\right)^{\alpha}\left(y_{i}^{M}\right)^{\gamma}\left(z_{i}^{M}\right)^{1-\alpha-\gamma}+\kappa \log \left(1-l_{i}^{M}\right), \quad 0 \leq l_{i}^{M} \leq 1
$$

subject to the budget constraint $x_{i}^{M}+p_{y} y_{i}^{M}+p_{z} z_{i}^{M} \leq w^{M} l_{i}^{M}+s_{i}^{M} \Pi^{M}$.

Solving first order conditions, we get

$$
\begin{aligned}
& \frac{\partial u_{i}^{M}}{\partial x_{i}^{M}}=\alpha\left(x_{i}^{M}\right)^{\alpha-1}\left(y_{i}^{M}\right)^{\gamma}\left(z_{i}^{M}\right)^{1-\alpha-\gamma}=\lambda_{i}^{M} \\
& \frac{\partial u_{i}^{M}}{\partial y_{i}^{M}}=\gamma\left(x_{i}^{M}\right)^{\alpha}\left(y_{i}^{M}\right)^{\gamma-1}\left(z_{i}^{M}\right)^{1-\alpha-\gamma}=\lambda_{i}^{M} p_{y} \\
& \frac{\partial u_{i}^{M}}{\partial z_{i}^{M}}=(1-\alpha-\gamma)\left(x_{i}^{M}\right)^{\alpha}\left(y_{i}^{M}\right)^{\gamma}\left(z_{i}^{M}\right)^{-\alpha-\gamma}=\lambda_{i}^{M} p_{z} \\
& -\frac{\kappa}{1-l_{i}^{M}}+\lambda_{i}^{M} w^{M}=0 \\
& x_{i}^{M}+p_{y} y_{i}^{M}+p_{z} z_{i}^{M}=w^{M} l_{i}^{M}+s_{i}^{M} \Pi^{M}
\end{aligned}
$$




\section{Equilibrium in Cournot duopoly}

With perfectly symmetric agents in each country, goods consumptions and/or labour supply must be the same for all agents within each country. Incorporating these symmetric conditions, we can drop the individual index subscript $i$ in the equilibrium equations.

Goods supplies are $\bar{x}$ units of good $x$ and $\bar{y}$ units of good $y$ and we have the following market clearing conditions.

$$
\begin{aligned}
& x^{H}+x^{F}+x^{M}=\bar{x} \\
& y^{H}+y^{F}+y^{M}=\bar{y}
\end{aligned}
$$

Dividing $\left(\right.$ E. $\left.2^{\mathrm{H}}\right)$ by $\left(\right.$ E. $\left.1^{\mathrm{H}}\right),\left(\mathrm{E} .2^{\mathrm{F}}\right)$ by $\left(\mathrm{E} .1^{\mathrm{F}}\right)$, and $\left(\mathrm{E} .2^{\mathrm{M}}\right)$ by $\left(\mathrm{E} .1^{\mathrm{M}}\right)$ dropping subscript $i$, we get

$$
\frac{x^{H}}{y^{H}}=\frac{x^{F}}{y^{F}}=\frac{x^{M}}{y^{M}}=\left(\frac{\alpha}{\gamma}\right) p_{y} .
$$

Dividing $\left(\mathrm{E}^{\mathrm{H}}{ }^{\mathrm{H}}\right)$ by $\left(\mathrm{E} .1^{\mathrm{H}}\right),\left(\mathrm{E} .3^{\mathrm{F}}\right)$ by $\left(\mathrm{E} .1^{\mathrm{F}}\right)$, and $\left(\mathrm{E} .3^{\mathrm{M}}\right)$ by $\left(\mathrm{E} .1^{\mathrm{M}}\right)$ dropping subscript $i$, we get

$$
\frac{x^{H}}{z^{H}}=\frac{x^{F}}{z^{F}}=\frac{x^{M}}{z^{M}}=\left(\frac{\alpha}{1-\alpha-\gamma}\right) p_{z} .
$$

Dividing $\left(\mathrm{E} .3^{\mathrm{H}}\right)$ by $\left(\mathrm{E} .2^{\mathrm{H}}\right),\left(\mathrm{E} .3^{\mathrm{F}}\right)$ by $\left(\mathrm{E} .2^{\mathrm{F}}\right)$, and $\left(\mathrm{E} .3^{\mathrm{M}}\right)$ by $\left(\mathrm{E} .2^{\mathrm{M}}\right)$ dropping subscript $i$, we get

$$
\frac{y^{H}}{z^{H}}=\frac{y^{F}}{z^{F}}=\frac{y^{M}}{z^{M}}=\left(\frac{\gamma}{1-\alpha-\gamma}\right) \frac{p_{z}}{p_{y}}
$$

Now, let's solve for the equilibrium goods prices. From (9) (11),

$$
x^{H}+x^{F}+x^{M}=\bar{x}=\left(y^{H}+y^{F}+y^{M}\right)\left(\frac{\alpha}{\gamma}\right) p_{y}=\left(\frac{\alpha}{\gamma}\right) p_{y} \bar{y}
$$

Hence, 


$$
p_{y}=\frac{\bar{x}}{\alpha \bar{y}}
$$

From (12) and (1),

$$
x^{H}+x^{F}+x^{M}=\bar{x}=\left(z^{H}+z^{F}+z^{M}\right)\left(\frac{\alpha}{1-\alpha-\gamma}\right) p_{z}=A\left(l^{F}+l^{M}\right)\left(\frac{\alpha}{1-\alpha-\gamma}\right) p_{z}
$$

Hence,

$$
p_{z}=\left(\frac{1-\alpha-\gamma}{\alpha}\right) \frac{\bar{x}}{A\left(l^{F}+l^{M}\right)}
$$

Given goods prices, we can get the equilibrium goods demand. Substituting for $p_{y} y^{H}$ and $p_{Z} z^{H}$ from (11) and (12) into (E. $\left.4^{\mathrm{H}}\right)$ with $s_{i}^{x}=1$ and dropping the subscript $i$, we get

$$
x^{H}+p_{y} y^{H}+p_{z} z^{H}=x^{H}+\left(\frac{\gamma}{\alpha}\right) x^{H}+\left(\frac{1-\alpha-\gamma}{\alpha}\right) x^{H}=\left(\frac{1}{\alpha}\right) x^{H}=\bar{x}
$$

Hence,

$$
x^{H}=\alpha \bar{x}
$$

From this result, (11), and (15), we have

$$
y^{H}=\left(\frac{\gamma}{\alpha}\right) \frac{x^{H}}{p_{y}}=\alpha \bar{y}
$$

Similarly, from equations (12) and (16), we have

$$
z^{H}=\left(\frac{1-\alpha-\gamma}{\alpha}\right) \frac{x^{H}}{p_{z}}=\alpha A\left(l^{F}+l^{M}\right)=\alpha Z
$$

where $\mathrm{Z}=\mathrm{Z}^{F}+\mathrm{Z}^{M}$ is the aggregate world oil supply. We can see here that Home agent's goods consumption is proportional to his contribution to the world goods supply via his good $x$ 
endowment. The proportionality constant is given by his contribution of good $x$ in the world market (= one) times the share of good $x$ in the consumers' utility due to goods consumption $(=\alpha$ for all consumers).

For the Foreign agent, substituting for $p_{y} y^{F}$ and $p_{z} z^{F}$ from (11) and (12) into (E. $\left.5^{\mathrm{F}}\right)$ with $s_{i}^{y}=$ $s_{i}^{F}=1$ and dropping the subscript $i$, we get

$$
x^{F}+p_{y} y^{F}+p_{z} z^{F}=\left(\frac{1}{\alpha}\right) x^{F}=p_{y} \bar{y}+w^{F} l^{F}+\Pi^{F}=p_{y} \bar{y}+p_{z} A l^{F}
$$

We have substituted for $\prod^{F}$ from (3).

Hence,

$$
\begin{aligned}
& x^{F}=\alpha\left(p_{y} \bar{y}+p_{z} A l^{F}\right)=\frac{\gamma l^{M}+(1-\alpha) l^{F}}{l^{F}+l^{M}} \bar{x} \equiv v^{F} \bar{x} \\
& y^{F}=\left(\frac{\gamma}{\alpha}\right) \frac{x^{F}}{p_{y}}=\frac{\gamma l^{M}+(1-\alpha) l^{F}}{l^{F}+l^{M}} \bar{y}=v^{F} \bar{y} \\
& z^{F}=\left(\frac{1-\alpha-\gamma}{\alpha}\right) \frac{x^{F}}{p_{z}}=\gamma A l^{M}+(1-\alpha) A l^{F}=v^{F} A\left(l^{F}+l^{M}\right)=v^{F} Z
\end{aligned}
$$

We can check here that Foreign agent's goods consumption is also proportional to his contribution to world supply of goods with the proportionality constant being $v^{F} \equiv \gamma+(1-a-\gamma) l^{F}$ / $\left(l^{F}+l^{M}\right)$, i.e. his contribution via good $y$ endowment share $(=$ one) times good $y$ 's share in consumers' utility $(=\gamma)$ plus his contribution via oil supply $\left(=l^{F} /\left(l^{F}+l^{M}\right)\right)$ times the share of oil in the utility $(=(1-a-\gamma)$ for all consumers).

Similarly, for the Middle agent, substituting for $p_{y} y^{M}$ and $p_{z} z^{M}$ from (11) and (12) into (E. $5^{\mathrm{M}}$ ) with $s_{i}^{M}=1$ and dropping the subscript $i$, we get

$$
x^{M}+p_{y} y^{M}+p_{z} z^{M}=\frac{1}{\alpha} x^{M}=w^{M} l^{M}+\Pi^{M}=p_{z} A l^{M}
$$

We have substituted for $\prod^{M}$ from (5).

Hence,

$$
x^{M}=\alpha p_{z} A l^{M}=\frac{(1-\alpha-\gamma) l^{M}}{l^{F}+l^{M}} \bar{x} \equiv v^{M} \bar{x}
$$




$$
\begin{aligned}
& y^{M}=\left(\frac{\gamma}{\alpha}\right) \frac{x^{M}}{p_{y}}=\frac{(1-\alpha-\gamma) l^{M}}{l^{F}+l^{M}} \bar{y}=v^{M} \bar{y} \\
& z^{M}=\left(\frac{1-\alpha-\gamma}{\alpha}\right) \frac{x^{M}}{p_{z}}=(1-\alpha-\gamma) A l^{M}=v^{M} A\left(l^{F}+l^{M}\right)=v^{M} Z
\end{aligned}
$$

where the proportionality constant equals $v^{M} \equiv(1-\alpha-\gamma) l^{M} /\left(l^{F}+l^{M}\right)$, i.e. Middle agent's contribution to the world goods supply via oil production $l^{M} /\left(l^{F}+l^{M}\right)$ times oil's share in the consumers' utility $(=(1-\alpha-\gamma))$.

We can see here that Home agent's good $x$ and good $y$ demands are purely given by good $x$ endowment, $\bar{x}$, good $y$ endowment, $\bar{y}$, and parameter $\alpha$, but Home agent's oil demand and Foreign and Middle agents' demands have the unknown labour supplies $l^{F}$ and $l^{M}$ yet in their solutions.

Now let's solve for the equilibrium shadow prices, i.e., the Lagrange multipliers of the budget constraints. This is required for the equilibrium labour supply evaluation later. From $\left(\mathrm{E} .1^{\mathrm{H}}\right),\left(\mathrm{E} .1^{\mathrm{F}}\right)$, and $\left(\right.$ E. $\left.1^{\mathrm{M}}\right)$ dropping subscript $i$ and using $(17) \sim(25)$, we get

$$
\lambda^{H}=\lambda^{F}=\lambda^{M}=\alpha(\bar{x})^{\alpha-1}(\bar{y})^{\gamma}\left(A\left(l^{F}+l^{M}\right)\right)^{1-\alpha-\gamma}
$$

Now, we can evaluate the equilibrium labour supplies of the Foreign and Middle agents in oil production. Substituting for $\lambda^{F}$ and $\lambda^{M}$ from (26) into (E. $\left.4^{\mathrm{F}}\right)$ and (E.4 $\left.4^{\mathrm{M}}\right)$ respectively dropping subscript $i$, we get the following two equations.

$$
\begin{aligned}
& w^{F}=\frac{\kappa}{\alpha(\bar{x})^{\alpha-1}(\bar{y})^{\gamma}\left(A\left(l^{F}+l^{M}\right)\right)^{1-\alpha-\gamma}\left(1-l^{F}\right)} \\
& w^{M}=\frac{\kappa}{\alpha(\bar{x})^{\alpha-1}(\bar{y})^{\gamma}\left(A\left(l^{F}+l^{M}\right)\right)^{1-\alpha-\gamma}\left(1-l^{M}\right)}
\end{aligned}
$$

We can see here that the labour wages $w^{F}$ and $w^{M}$ are both functions of $l^{F}$ and $l^{M}$. That is, labour wages are determined not only by domestic labour supply but also by the other country's labour supply. We have an externality in labour market in our oil production duopoly even though labour is internationally immobile. Taking derivatives $\partial w^{F} / \partial l^{F}$ and $\partial w^{M} / \partial l^{M}$ from (27) and (28) and $\partial p_{z} / \partial l^{F}=\partial p_{z} / \partial l^{M}$ from (16) and substituting into the Euler equations of oil monopolists, $\left(\right.$ E. $\left.\mathrm{O}^{\mathrm{F}}\right)$ and $\left(\mathrm{E} . \mathrm{O}^{\mathrm{M}}\right)$, we get the following reaction functions. ${ }^{8}$

\footnotetext{
${ }^{8}$ ref. Appendix A for details.
} 


$$
\begin{aligned}
& (1-\alpha-\gamma)(\bar{x})^{\alpha}(\bar{y})^{\gamma}\left(A\left(l^{F}+l^{M}\right)\right)^{1-\alpha-\gamma}\left(1-l^{F}\right)^{2} l^{M} \\
& =\kappa\left(l^{F}+l^{M}\right)^{2}-\kappa(1-\alpha-\gamma)\left(1-l^{F}\right)\left(l^{F}+l^{M}\right) l^{F}
\end{aligned}
$$

(Foreign oil producer's reaction function)

$$
\begin{aligned}
& (1-\alpha-\gamma)(\bar{x})^{\alpha}(\bar{y})^{\gamma}\left(A\left(l^{F}+l^{M}\right)\right)^{1-\alpha-\gamma}\left(1-l^{M}\right)^{2} l^{F} \\
& =\kappa\left(l^{F}+l^{M}\right)^{2}-\kappa(1-\alpha-\gamma)\left(1-l^{M}\right)\left(l^{F}+l^{M}\right) l^{M}
\end{aligned}
$$

(Middle oil producer's reaction function)

Equations (29) and (30) are two main reaction functions in Cournot oil supply duopoly. These are non-linear equations in $l^{F}$ and $l^{M}$. Foreign oil producer solves for $l^{F}$ taking Middle oil producer's action $l^{M}$ as given.

$$
\hat{l}^{F}=l^{F}\left(\bar{l}^{M}\right)^{*}
$$

Middle oil producer solves for $l^{M}$ taking Foreign oil producer's action $l^{F}$ as given.

$$
\hat{l}^{M}=l^{M}\left(\bar{l}^{F}\right)^{*}
$$

Then the two equilibrium values of $\left(l^{F}\right)^{*}$ and $\left(l^{M}\right)^{*}$ are obtained by solving these two equations simultaneously by setting $\left(l^{F}\right)^{*}=l^{F}\left(\hat{l}^{M}\right)$ and $\left(l^{M}\right)^{*}=l^{M}\left(\hat{l}^{F}\right)$.

Notice that $l^{F}$ and $l^{M}$ enter (29) and (30) perfectly symmetrically, so we can set $l^{F}=l^{M}$. We show the reaction curves in Figure 1. We can see here that there is a non-trivial Cournot equilibrium for $l^{F}=l^{M} \in(0,1)$.

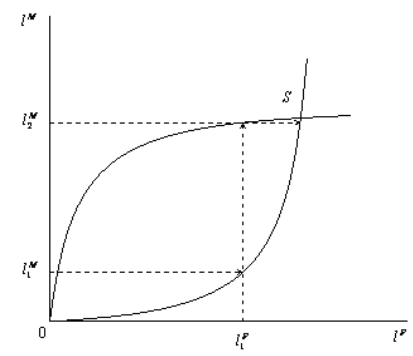

Figure 1. Reaction curves under Cournot duopoly (Convex curve in the figure is for the Foreign oil producer and concave curve is for the Middle oil producer) 
Let's now solve the Cournot equilibrium explicitly. We can substitute $l^{F}=l^{M}$ in equation (29) and solve for $l^{F}$.

$$
(1-\alpha-\gamma)(\bar{x})^{\alpha}(\bar{y})^{\gamma}\left(2 A l^{F}\right)^{1-\alpha-\gamma}\left(1-l^{F}\right)^{2} l^{F}=\kappa\left(2 l^{F}\right)^{2}-\kappa(1-\alpha-\gamma)\left(1-l^{F}\right)\left(2 l^{F}\right) l^{F}
$$

Dividing both sides by $\left(1-l^{F}\right)^{2} l^{F}$ for $l^{F} \neq 0$, we get

$$
(1-\alpha-\gamma)(\bar{x})^{\alpha}(\bar{y})^{\gamma}\left(2 A l^{F}\right)^{1-\alpha-\gamma}=\frac{2 \kappa l^{F}}{1-l^{F}}\left\{\frac{2}{1-l^{F}}-(1-\alpha-\gamma)\right\}
$$

The left-hand side (LHS) of (31) is a monotonically increasing concave function in $l^{F}$ and the right-hand side (RHS) is a monotonically increasing convex function. We can further check that the slope of the LHS at $l^{F}=0$ becomes +infinity, $\lim _{l^{F}} \partial L H S / \partial l^{F}=+\infty$, and the slope of the RHS at $l^{F}=0$ is positive and finite, $0<\partial R H S /\left.\partial l^{F}\right|_{l^{F}=0}=2 \kappa[2-(1-\alpha-\gamma)]<+\infty$, with $L H S=R H S=0$ at $l^{F}=0$. Secondly, we also get $0<\lim _{I^{F} \rightarrow 1^{\uparrow}} L H S=(1-\alpha-\gamma)(\bar{x})^{\alpha}(\bar{y})^{\gamma}(2 A)^{1-\alpha-\gamma}<+\infty$ and $\lim R H S=+\infty$. Hence, we can conclude here that we have a unique non-trivial solution to (31) $l_{\text {for }}^{l^{\uparrow}} l^{F} \in(0,1)$ and a trivial solution $l^{F}=0$. This is shown in Figure 2. Using Maple for the parameter and exogenous variable values of Table 1 , we get $l_{\text {Cournot }}^{F}=l_{\text {Cournot }}^{M}=0.520 .{ }^{9}$

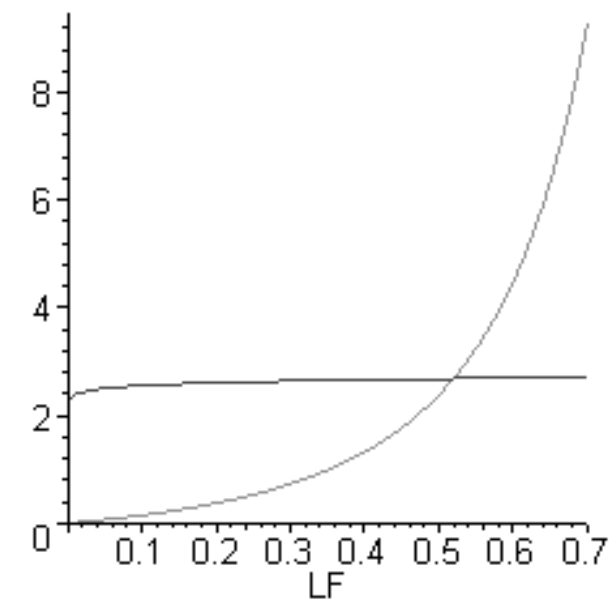

Figure 2. Equilibrium labour supply of the representative Foreign consumer agent in Cournot oil duopoly

\footnotetext{
${ }^{9}$ I set parameter values $\alpha=0.41$ and $\gamma=0.56$ according to the GDP shares of the non-OPEC oil producing countries and non-oil producing industrialized countries as specified in the Introduction. I assume in my study that the three groups of countries constitute the whole world economy. I use Maple 8.0 for all the numerical evaluations.
} 
Table 1

Values of parameters and exogenous variables

\begin{tabular}{c|c|c|c|c|c|c|c|c}
\hline parameters/variables & $\alpha$ & $\gamma$ & $\kappa$ & $A$ & $\bar{x}$ & $\bar{y}$ & $l^{F}$ & $l^{M}$ \\
\hline \hline value/range & 0.41 & 0.56 & 0.3 & 50 & 80 & 100 & {$[0,1]$} & {$[0,1]$} \\
\hline
\end{tabular}

We also get from (27) and (28) $w_{\text {Cournot }}^{F}=w_{\text {Cournot }}^{M}=1.362$ for the parameter values of Table 1 . This result illustrates the factor price equalization property, $w^{F}=w^{M}$, as predicted by the standard international trade theory. I.e., although labour is internationally immobile, wage rates are equalized between Foreign and Middle through the trade of oil, in which labour is used as a production factor.

\section{Competitive oil supply}

In this section, we go through the same procedure for the competitive oil supply case as for the duopoly case of sections 2 and 3 .

\subsection{Oil producer’s problem}

In the competitive oil supply case, there is a continuum of identical oil producers in each of Foreign and Middle countries. All oil producers have an identical oil production function given by equation (1) and produce oil hiring labour from their own domestic consumer agents like in the duopoly case. The oil trading and other processes are exactly the same as in the duopoly case. We get the following Euler equations for labour input instead of equations $\left(\mathrm{E} . \mathrm{O}^{\mathrm{F}}\right)$ and $\left(\mathrm{E} . \mathrm{O}^{\mathrm{M}}\right)$ of the duopoly model.

$$
p_{z} A-w^{F}=0
$$

(Competitive oil supply, Foreign oil producers)

$$
p_{z} A-w^{M}=0
$$

(Competitive oil supply, Middle oil producers) 


\subsection{Representative agent's problem}

We can assume without loss of generality that any Foreign or Middle agent holds the same share of each of the identical domestic oil companies, so we can use the same budget constraints as in the duopoly model with the same $s_{i}^{F}$ and $s_{i}^{M}$ accordingly. Hence, we get the identical Euler equations for the Foreign and Middle consumer agents as in $\left(\mathrm{E} .1^{\mathrm{F}}\right) \sim\left(\mathrm{E} .5^{\mathrm{F}}\right)$ and $\left(\mathrm{E} .1^{\mathrm{M}}\right) \sim\left(\mathrm{E} .5^{\mathrm{M}}\right)$. Representative Home agent's Euler equations remain unchanged as in $\left(\right.$ E. $\left.1^{\mathrm{H}}\right) \sim\left(\mathrm{E} .4^{\mathrm{H}}\right)$. Given morphologically identical Euler equations for consumer agents, we get exactly the same equilibrium goods prices, goods demand, etc. except equilibrium labour supplies in oil production of the Foreign and Middle consumer agents.

Let's substitute for $w^{F}$ and $w^{M}$ from $\left(\mathrm{E} . \mathrm{O}^{\mathrm{Fc}}\right)$ and $\left(\mathrm{E} . \mathrm{O}^{\mathrm{Mc}}\right)$ into $\left(\mathrm{E} .4^{\mathrm{F}}\right)$ and $\left(\mathrm{E} .4^{\mathrm{M}}\right)$ respectively.

$$
\begin{aligned}
& \frac{\kappa}{1-l_{i}^{F}}=\lambda_{i}^{F} p_{z} A \\
& \frac{\kappa}{1-l_{i}^{M}}=\lambda_{i}^{M} p_{z} A
\end{aligned}
$$

Substituting here for $p_{z}$ from (16) and for $\lambda_{i}^{F}$ and $\lambda_{i}^{M}$ from (26) dropping subscript $i$, we get with rearrangements

$$
(1-\alpha-\gamma)(\bar{x})^{\alpha}(\bar{y})^{\gamma}\left(A\left(l^{F}+l^{M}\right)\right)^{1-\alpha-\gamma}=\frac{\kappa\left(l^{F}+l^{M}\right)^{2}}{1-l^{F}}
$$

(Foreign's equilibrium condition; competitive oil supply)

$$
(1-\alpha-\gamma)(\bar{x})^{\alpha}(\bar{y})^{\gamma}\left(A\left(l^{F}+l^{M}\right)\right)^{1-\alpha-\gamma}=\frac{\kappa\left(l^{F}+l^{M}\right)^{2}}{1-l^{M}}
$$

(Middle's equilibrium condition; competitive oil supply)

We can see in (32) and (33) that $l^{F}=l^{M}$ for all values of $l^{F}, l^{M} \in[0,1]$ because $l^{F}$ and $l^{M}$ enter the equations symmetrically. Now let's substitute $l^{F}=l^{M}$ in (32) and solve for $l^{F}$.

$$
(1-\alpha-\gamma)(\bar{x})^{\alpha}(\bar{y})^{\gamma}\left(2 A l^{F}\right)^{1-\alpha-\gamma}=\frac{4 \kappa\left(l^{F}\right)^{2}}{1-l^{F}}
$$

The left-hand side of (34) is a monotonically increasing concave function of $l^{F}$ and the right- 
hand side is a monotonically increasing convex function. As in the oil duopoly case of (31), we can check that the slope of the LHS of (34) at $l^{F}=0$ becomes + infinity, $\lim _{l^{F}} \partial L H S / \partial l^{F}=+\infty$, and the slope of the RHS at $l^{F}=0$ is $+0, \lim \partial R H S / \partial l^{F}=+0$, , with $L H S=R H S=0$ at $l^{F}=0$. Secondly, we also get $0<\lim _{I^{F} \rightarrow \uparrow^{\uparrow}} L H S=\left(1^{l^{F} \rightarrow 0 \downarrow}-\gamma\right)(\bar{x})^{\alpha}(\bar{y})^{\gamma}(2 A)^{1-\alpha-\gamma}<+\infty$ and $\lim _{f^{F} \rightarrow 1^{\uparrow}} R H S=+\infty$. Hence, we can again conclude $l^{F} \mathbb{1}^{\uparrow}$ that we have a unique non-trivial solution for $l^{F}$ here apart from $l^{F}=0$. We get $l_{\text {competitive }}^{F}=l_{\text {competitive }}^{M}=0.819>0.520=l_{\text {Cournot }}^{F}=l_{\text {Cournot }}^{M}$ using Maple. We also get from (27) and (28) $w_{\text {competitive }}^{F}=w_{\text {competitive }}^{M}=3.572>1.362=w_{\text {Cournot }}^{F}=w_{\text {Cournot }}^{M}$ for the parameter values of Table 1 .

\section{Welfare comparison}

We have solved the equilibrium for Cournot duopoly in section 3 and for the competitive case in section 4. All the endogenous variables such as oil price and goods demand are given as functions of labour inputs, $l^{F}$ and $l^{M}$, or of exogenous variables only. Therefore, if we solve for the equilibrium labour inputs, then other variables are automatically solved for. We have calculated the equilibrium labour inputs in sections 3 and 4 for parameter and exogenous variable values of Table 1 of section 3. Furthermore, we run a simulation for wider range of parameter and exogenous variable values to check the robustness of the prediction of the model. We compare the effects of the change from competitive oil supply to Cournot duopoly, taking the competitive case as a benchmark.

\subsection{Equilibrium welfare}

Equilibrium labour input, oil supply and goods prices etc. are summarized in Table 2. We can see here that labour supply by representative Foreign and Middle agents has both fallen from 0.819 units for competitive oil supply to 0.520 units for Cournot duopoly. This amounts to a $36.6 \%$ reduction of aggregate oil supply of both countries for the change from competitive to Cournot duopoly. This is a natural drop in oil supply due to duopoly inefficiency. Foreign and Middle agents have identical oil production function and identical preferences in goods consumption and leisure. Furthermore, utility function of Foreign and Middle agents is additively separable in goods consumption and leisure. Therefore, we get identical labour supplies between Foreign and Middle in each competition structure. As a result, good $x$ price and good $y$ price remain unchanged. Equilibrium oil price, $p_{z}$, has risen from 0.071 to 0.113 and this amounts to a proportionately much higher $57.6 \%$ increase than the oil supply reduction. This is due to the fact that labour input enters oil price equation inversely (ref. equation (16)). We can also see here that wage rate is much higher under perfect competition than under Cournot duopoly. This can be explained by the very high marginal rate of substitution between goods consumption and leisure at the very low level of leisure under perfect competition for Foreign and Middle agents. Price elasticity of oil demand remains unchanged at minus unity in both cases. 
Table 2

Equilibrium labour input, oil supply, and goods prices etc.

\begin{tabular}{c|c|c}
\hline & perfect competition & Cournot duopoly \\
\hline \hline Foreign agent's labour input, $l^{F}$ & 0.819 & 0.520 \\
Middle agent's labour input, $l^{M}$ & 0.819 & 0.520 \\
Aggregate labour input, $l^{F}+l^{M}$ & 1.639 & 1.039 \\
Foreign agent's oil supply, $A l^{F}$ & 40.97 & 25.99 \\
Middle agent's oil supply, $A l^{M}$ & 40.97 & 25.99 \\
Good $x$ price, $p_{x}$ & 1 & 1 \\
Good $y$ price, $p_{y}$ & 1.093 & 1.093 \\
Oil price, $p_{z}$ & 0.071 & 0.113 \\
Wage rate, $w^{F}=w^{M}$ & 3.572 & 1.362 \\
Elasticity of oil demand & -1 & -1 \\
\hline
\end{tabular}

Let us compare the welfare between perfect competition and Cournot duopoly. In Table 3, we show the equilibrium goods demand, utility and welfare change. We can see here several attractive results. First of all, good $x$ demand and good $y$ demand do not change for all three agents. This is natural because with Cobb-Douglas preferences agents spend fixed portion of wealth on each good, and given unchanged good $x$ and good $y$ prices and real wealth, agents' good $x$ and good $y$ demand would not change either. Note that the price elasticity of oil demand is -1 and so oil revenue does not change for different level of oil supply. Oil demand falls substantially by $36.6 \%$ for Home and Middle agents and by a greater $44.8 \%$ for Foreign agents under Cournot duopoly. As a result, Home agent's utility falls a little by $1.4 \%$ under Cournot duopoly. For the Foreign agent, despite being a duopolist in oil supply Cournot competition, his utility has fallen by about $0.8 \%$ under Cournot duopoly. This result shows that the Foreign agent, as a duopolist in oil supply Cournot competition, cannot do better and is actually worse off under duopoly compared to perfect competition despite being a duopolist. Why do we get this result? First of all, we can observe from Tables 2 and 3 that Foreign is a net buyer of oil while Middle is a net seller. The oil supply/oil consumption ratio for the Foreign is 0.87 in both competitive and Cournot cases. The corresponding ratio is 33.3 for the Middle in both cases. Hence, Foreign suffers a loss and Middle 
gains a huge profit from higher oil price under Cournot duopoly. We can think of it as the worsening terms-of-trade effect for Foreign agents, i.e. $p_{y} / p_{z}$ becomes lower under oil duopoly. Firstly, Foreign agents supply less labour in oil production but earn the same oil revenue under duopoly. Secondly, Foreign agents have to pay for their own oil consumption at a higher price, so they reduce their oil consumption but still remain net buyers of oil. Even worse, their endowment of good $y$ now becomes less valuable compared to oil. Hence, Foreign agents actually suffer more from higher oil price and lower value of their endowment than benefit from higher level of leisure. This leads to a lower welfare level for Foreign agents under Cournot duopoly than under perfect competition. In contrast, Middle agents' labour supply has also fallen by $36.6 \%$ and hence their utility from leisure has risen accordingly under duopoly. Overall, their welfare level has risen greatly by about $32.4 \%$ and this result is understandable given their net seller position by a huge margin in the oil market. I.e., Middle agents benefit from higher oil price because they are net sellers of oil. Moreover, Middle agents just optimize between consumption of goods and leisure by choosing their labour supply in oil production and do not suffer from any loss in their endowment value. Overall, the positive effects of higher oil profit and higher level of leisure outweigh the negative effect of their decreased oil consumption, so Middle agents' utility has risen considerably. To put it differently, Foreign oil producers as well as Middle oil producers now face a formidable opponent under duopoly. Their opponents now have a market power. They are now no infinitesimal players in the oil market. Duopoly brings about risk as well as opportunity, especially for Foreign agents. As a whole, the world welfare is $0.7 \%$ lower under Cournot duopoly compared to competitive oil supply case.

Table 3

Equilibrium goods demand, oil demand, and welfare

\begin{tabular}{|c|c|c|c|c|}
\hline & \multicolumn{2}{|c|}{ Home agents } & \multicolumn{2}{|c|}{ Foreign agents } \\
\hline & $\mathrm{PC}^{\mathrm{a}}$ & Cournot $^{\mathrm{b}}$ & $\mathrm{PC}^{\mathrm{a}}$ & Cournot $^{b}$ \\
\hline Good $x$ demand & 32.8 & 32.8 & 46.0 & 46.0 \\
\hline Good $y$ demand & 41.0 & 41.0 & 57.5 & 57.5 \\
\hline Oil demand, $z$ & 33.59 & 21.31 & 47.11 & 29.88 \\
\hline Leisure & 1 & 1 & 0.181 & 0.480 \\
\hline Utility & 37.19 & 36.69 & 51.65 & 51.23 \\
\hline Welfare gain/loss & NA & $\begin{array}{c}-0.014 \\
(=-1.4 \%)\end{array}$ & NA & $\begin{array}{c}-0.008 \\
(=-0.8 \%)\end{array}$ \\
\hline
\end{tabular}

a. $\mathrm{PC}=$ perfect competition, $\mathrm{b}$. Cournot $=$ Cournot duopoly. 
Table 3 (continued)

\begin{tabular}{c|c|c|c|c}
\hline \multirow{2}{*}{} & \multicolumn{2}{|c|}{ Middle agents } & \multicolumn{2}{c}{ World } \\
\cline { 2 - 5 } & $\mathrm{PC}^{\mathrm{a}}$ & Cournot $^{\mathrm{b}}$ & $\mathrm{PC}^{\mathrm{a}}$ & Cournot $^{\mathrm{b}}$ \\
\hline \hline Good $x$ demand & 1.2 & 1.2 & 80 & 80 \\
Good $y$ demand & 1.5 & 1.5 & 100 & 100 \\
Oil demand, $z$ & 1.23 & 0.78 & 81.94 & 51.97 \\
Leisure & 0.181 & 0.480 & $\mathrm{NA}$ & $\mathrm{NA}$ \\
Utility & 0.85 & 1.12 & 89.69 & 89.04 \\
Welfare gain/loss & $\mathrm{NA}$ & $\begin{array}{c}+0.324 \\
(=+32.4 \%)\end{array}$ & $\mathrm{NA}$ & $\begin{array}{c}-0.007 \\
(=-0.7 \%)\end{array}$ \\
\hline
\end{tabular}

\subsection{Simulation}

As the two equilibrium equations (31) for Cournot duopoly and (34) for perfect competition are non-linear, so it is difficult to prove analytically the welfare implications for the Foreign country. Instead I have run a simulation using Maple for wide range of parameter/exogenous variable values given in Table 4. The parameter values are set with the following assumptions. First, total oil production would be between at most $2 \%$ and $200 \%$ of either good $x$ or good $y$ in physical terms, i.e. $\frac{Z}{\bar{x}}=\frac{A\left(l^{F}+l^{M}\right)}{\bar{x}}=\frac{2 A l^{F}}{\bar{x}} \in[0.02,2.0]$ and similarly for $\frac{Z}{\bar{y}}$. Oil production productivity $A$ is assumed to range between 1 and 100, and good $x$ and good $y$ endowments both range from $A$ to 100 accordingly. Second, the weight on leisure in Foreign agents' utility function ranges between $10 \%$ and $200 \%$, i.e. $\kappa \in[0.1,2.0]$. Third, the indices $\alpha$ and $\gamma$ of the goods consumption in the utility function range from 0.05 to 0.9 and satisfy the necessary condition $0<\alpha+\gamma<1$. The increments are chosen to be 0.05 for $\alpha$ and $\gamma, 0.2$ for $\kappa$, and 20 for $A, \bar{x}$, and $\bar{y}$, to reflect both effectiveness (precision) and efficiency (computing time). Two separate simulation programs for Cournot duopoly and perfect competition are run on Maple and the total number of iterations is 94,050 each. $^{10}$

\footnotetext{
${ }^{10}$ Maple files are JLT_iteration_Cournot2.mws and JLT_iteration_competitive2.mws and are available from the author on request.
} 
Table 4

Range of values of parameters and exogenous variables for simulation $(0<\alpha+\gamma<1)$

\begin{tabular}{c|c|c|c|c|c|c|c|c}
\hline $\begin{array}{c}\text { parameters/ } \\
\text { variables }\end{array}$ & $\alpha$ & $\gamma$ & $\kappa$ & $A$ & $\bar{x}$ & $\bar{y}$ & $l^{F}$ & $l^{M}$ \\
\hline \hline range & {$[0.05,0.9]$} & {$[0.05,0.9]$} & {$[0.1,2.0]$} & {$[1,100]$} & {$[1,100]$} & {$[1,100]$} & {$[0,1]$} & {$[0,1]$} \\
\hline increments & 0.05 & 0.05 & 0.2 & 20 & 20 & 20 & - & - \\
\hline
\end{tabular}

I show here the summary features of the simulation. First, the number of cases in iterations where the Foreign welfare is higher under Cournot duopoly than under perfect competition, which I call 'welfare reversal,' is 1,385 out of 94,050 cases, i.e. the results of my model are reversed only for $1.47 \%$ of the time and remain robust for $98.53 \%$ of the time. Second, 961 cases out of 1,385 reversal cases happen when Foreign is a net oil exporter, i.e. when $\alpha>\gamma, 258$ cases happen when Foreign is a net importer of oil, i.e. when $\alpha<\gamma$, and 166 cases happen when Foreign is an oil autarky, i.e. when $\alpha=\gamma$. Note here that excess oil demand of Foreign is given as follows from (22) and (1).

$$
\text { Excessoil demand }=\left(Z^{F}\right)^{d}-\left(Z^{F}\right)^{s}=\gamma A l^{F}+(1-\alpha) A l^{F}-A l^{F}=A(\gamma-\alpha) l^{F}
$$

The above 1,385 cases of welfare reversal can be classified into the following three categories.

- First, net Foreign oil exporter, $\alpha>\gamma$, occurs mainly for small values of $\alpha$ across values of $\gamma$ up to $\gamma \leq 0.45$, and occurs only when $\bar{x}=1$ for $\alpha \geq 0.30$. That is, Foreign becomes net exporter of oil only when $H$ is a very small country for reasonable values of $\alpha$, which is quite unrealistic.

- Second, net Foreign oil importer, $\alpha<\gamma$, occurs mainly for small values of $\gamma$ across the values of $\alpha$ up to $\alpha \leq 0.45$, and occurs only when $\bar{y}=1$ for $\gamma \geq 0.20$. That is, Foreign becomes net importer of oil only when $F$ is a very small country for reasonable values of $\gamma$, which is also quite unrealistic.

- Third, oil autarky, $\alpha=\gamma$, occurs mainly for small values of $\alpha$ and $\gamma$, and becomes quickly rare and occurs only when $\bar{x}=\bar{y}=1$ as $\alpha$ and $\gamma$ get larger than or equal to 0.20 . That is, oil autarky occurs only when $H$ and $F$ are both very small countries for reasonable values of $\alpha$ and $\gamma$, which is highly unrealistic.

More specifically, Foreign welfare under Cournot duopoly is greater than that under perfect competition in the following circumstances.

- Welfare reversal occurs only for relatively large weight on leisure against goods consumption in the utility function, i.e. only when $\kappa \geq 0.9$ (ref. equation (7)). This is the 
case when the utility gain is quite high from more leisure.

- Welfare reversal occurs only when the oil production productivity is very low, i.e. only for $A=1$ in the simulation. This is the case when the return from investing more labour in oil production is relatively low and hence return from more leisure is relatively higher.

- For small to medium values of $\alpha$ coupled with medium to large values of $\gamma$, i.e. for $0.05 \leq$ $\alpha \leq 0.35$ and $0.40 \leq \gamma \leq 0.80$ with around $0.50 \leq \alpha+\gamma \leq 0.85$, welfare reversal does not happen for any values of $\bar{x}$ or $\bar{y}$. We can imagine that this covers most real world situations.

- For very small values of $\alpha$ and $\gamma$, i.e. for $0.05 \leq \alpha \leq 0.25$ and $0.05 \leq \gamma \leq 0.15$ with $\alpha+\gamma \leq$ 0.3 , welfare reversal happens for wide range of economy sizes of $H$ and $F$ represented by $\bar{x}$ and $\bar{y}$. This is the case where individuals regard good $x$ and good $y$ very poorly and values oil $(z)$ very highly (more than $70 \%$ of all goods consumption). This is highly unlikely in the real world.

- As $\alpha$ gets large, welfare reversal happens only for very small values of $\bar{x}$, i.e. only when $H$ is a very small country. However, this is unlikely in the real world.

- Similarly, as $\gamma$ gets large, welfare reversal happens only for very small values of $\bar{y}$, i.e. only when $F$ is a very small country except oil production. This is also unlikely.

- For small to large values of $\alpha$ coupled with medium to large values of $\gamma$ with around $0.35 \leq$ $\alpha+\gamma \leq 0.95$ except the above non-welfare reversal case, welfare reversal happens only for very small values of $\bar{x}$ and $\bar{y}$, i.e. only when $H$ and $F$ are both very small countries. This is again highly unlikely.

In summary, we can conclude that welfare reversal does not happen for most reasonable values of parameters and exogenous variables that reflect the real world. Consequently, the results of my model remain robust for wide range of parameter values. Figure 3 shows the cross-check diagram of parameter value ranges for welfare reversal. 


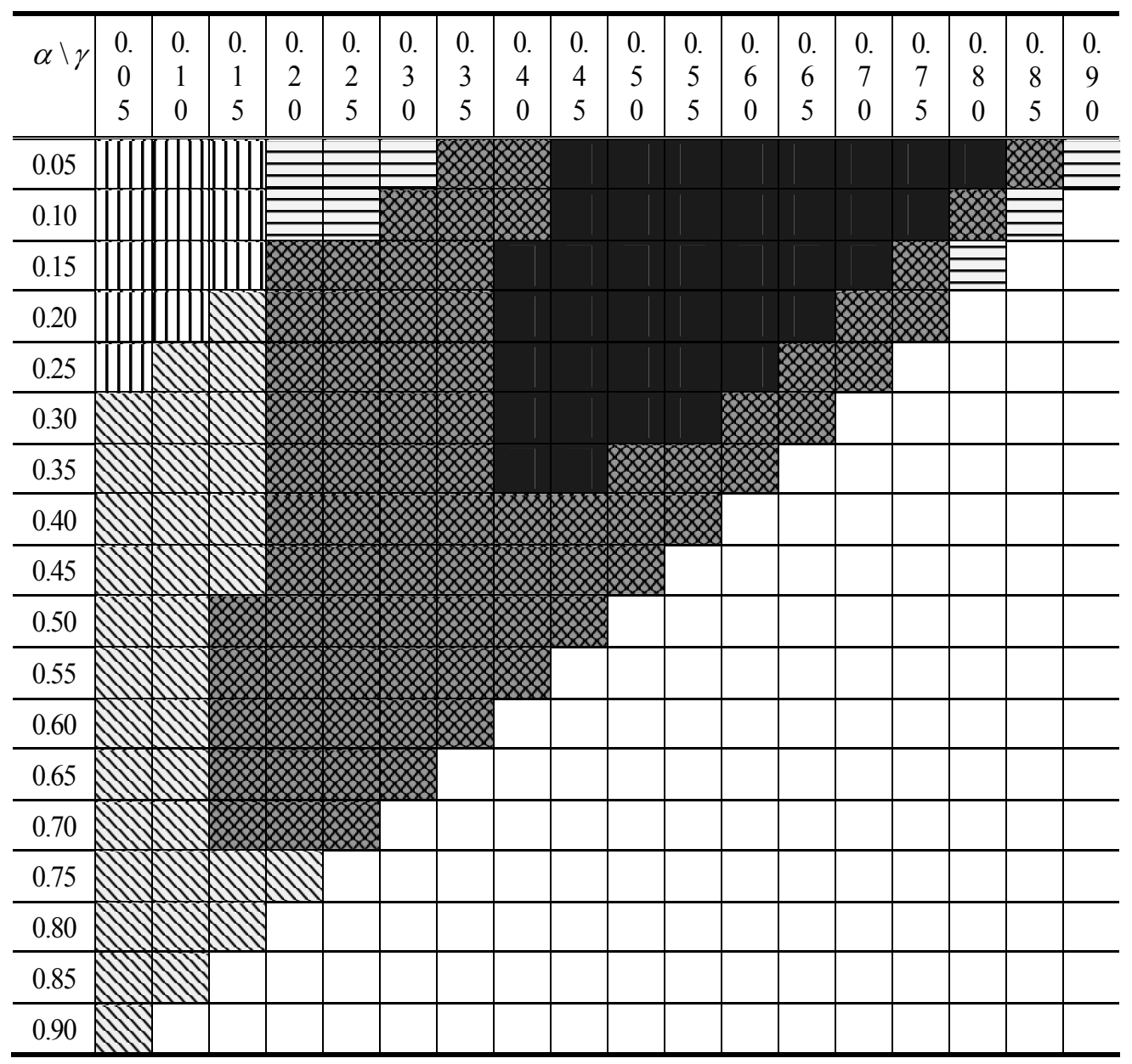

:Welfare reversal does not happen for any $\bar{x}$ or $\bar{y}$.

:Welfare reversal happens only when $\bar{x}=1$.

:Welfare reversal happens only when $\bar{y}=1$.

:Welfare reversal happens only when $\bar{x}=\bar{y}=1$.

: No restriction of $\bar{x}=1$ or $\bar{y}=1$ is required for welfare reversal.

: Infeasible region for $\{\alpha, \gamma\}$ because $0<\alpha+\gamma<1$.

Figure 3. Cross-check diagram of parameter value ranges for welfare reversal 


\section{Conclusion}

We have studied a general equilibrium model of trilateral trade with asymmetric supply/ demand market structure. We have introduced an oil duopoly with Cournot simultaneous move game in quantity by Foreign and Middle. Despite being a duopolist, Foreign is actually worse off under Cournot duopoly compared to perfect competition due to reduced oil consumption and worsening terms-of-trade effect. When Foreign remains a net buyer of oil, Foreign has to pay higher oil price under Cournot duopoly and also suffers loss of value in its good $y$ endowment due to worsening terms-of-trade effect. These negative effects outweigh the positive effect of more leisure under Cournot duopoly. Consequently, Foreign actually becomes worse off under Cournot duopoly despite being a duopolist in the oil market. When Foreign is a net seller of oil, loss from reduced oil consumption still dominates the gains from more leisure and higher oil price under oil duopoly because the oil revenue is constant but the marginal utility of leisure is now lower at higher level of leisure under duopoly. Hence, Foreign again loses out under oil duopoly when it is a net exporter of oil. When Foreign is an oil autarky, i.e. Foreign consumes just what it produces in oil, it suffers loss from lower oil consumption and gains from only higher level of leisure, without any additional gain from higher oil price under Cournot duopoly. Therefore, it is natural that Foreign is worse off under oil duopoly, comparing with the net seller case. In contrast, the pure oil duopolist Middle gains considerably under Cournot duopoly as it is always a net seller of oil and loses nothing in its endowment and hence benefits from higher oil price and more leisure. Perfect competition in oil supply is the best market structure in terms of global welfare and also for Home and Foreign agents.

We may extend the model as follows. First, we can introduce production of good $x$ and good $y$ rather than exogenously given endowments, e.g. using labour and capital as inputs. Second, we can also model oil supply as non-renewable resources, i.e. an extraction from finite reserves. This will change the structure of the model completely from the one we studied here. Third, we can introduce substitute goods for oil, e.g. natural gas or nuclear energy into the model and study the impacts of the presence of substitutes on the oil's duopoly power. Fourth, we can diversify the endowment ownership assumptions of Home and Foreign such that both Home and Foreign own a mix of good $x$ and good $y$ endowments to make the model more realistic.

\section{Acknowledgements}

I would like to thank Adrian Masters and Kenneth Burdett for their supervision and two anonymous referees, Pierre Regibeau, Alejandro Cunat, B.Y. Kim, and Xavier Mateos-Planas for their helpful comments. 


\section{References}

BP p.l.c. 2003. BP Statistical Review of World Energy. London.

Cox, J.C. and M. Walker. 1998. Learning to play Cournot duopoly strategies. Journal of Economic Behavior \& Organization. 36: 141-161.

Dowrick, S. 1986. von Stackelberg and Cournot duopoly: choosing roles. Rand Journal of Economics. 17: 251-260.

Lambertini, L. 1997. Prisoners' dilemma in duopoly (super) games. Journal of Economic Theory. 77: 181-191.

Lucas, R.E. Jr. 1982. Interest rates and currency prices in a two-country world. Journal of Monetary Economics. 10: 335-359.

Nero, G. 1996. A structural model of intra European union duopoly airline competition. Journal of Transportation and Policy. 30: 137-155.

Rees, R. 1993. Collusive equilibrium in the Great Salt duopoly. Economic Journal. 103: 833-848.

Singh, N. and X. Vives. 1984. Price and quantity competition in a differentiated duopoly. Rand Journal of Economics. 15: 546-554.

von Stackelberg, H. 1952. The theory of the market economy. Translated from German and with an Introduction by A.T. Peacock. William Hodge and Company Limited, London, United Kingdom.

United Nations. 2003. National accounts statistics: analysis of main aggregates 2001. New York. 


\section{Appendix. Derivation of reaction functions in labour supply, $l^{F}$ and $l^{M}$}

The marginal change of labour wage due to an extra unit of own labour supply is obtained from equations (27) and (28).

$$
\begin{aligned}
& \frac{\partial w^{F}}{\partial l^{F}}=-\frac{\kappa\left\{(1-\alpha-\gamma)\left(A\left(l^{F}+l^{M}\right)\right)^{-\alpha-\gamma} A\left(1-l^{F}\right)-\left(A\left(l^{F}+l^{M}\right)\right)^{1-\alpha-\gamma}\right\}}{\alpha(\bar{x})^{\alpha-1}(\bar{y})^{\gamma}\left\{\left(A\left(l^{F}+l^{M}\right)\right)^{1-\alpha-\gamma}\left(1-l^{F}\right)\right\}^{2}} \\
& =-\frac{\kappa\left(A\left(l^{F}+l^{M}\right)\right)^{-\alpha-\gamma}\left\{(1-\alpha-\gamma) A\left(1-l^{F}\right)-A\left(l^{F}+l^{M}\right)\right\}}{\alpha(\bar{x})^{\alpha-1}(\bar{y})^{\gamma}\left\{\left(A\left(l^{F}+l^{M}\right)\right)^{1-\alpha-\gamma}\left(1-l^{F}\right)\right\}^{2}} \\
& \frac{\partial w^{M}}{\partial l^{M}}=-\frac{\kappa\left\{(1-\alpha-\gamma)\left(A\left(l^{F}+l^{M}\right)\right)^{-\alpha-\gamma} A\left(1-l^{M}\right)-\left(A\left(l^{F}+l^{M}\right)\right)^{1-\alpha-\gamma}\right\}}{\alpha(\bar{x})^{\alpha-1}(\bar{y})^{\gamma}\left\{\left(A\left(l^{F}+l^{M}\right)\right)^{1-\alpha-\gamma}\left(1-l^{M}\right)\right\}^{2}} \\
& =-\frac{\kappa\left(A\left(l^{F}+l^{M}\right)\right)^{-\alpha-\gamma}\left\{(1-\alpha-\gamma) A\left(1-l^{M}\right)-A\left(l^{F}+l^{M}\right)\right\}}{\alpha(\bar{x})^{\alpha-1}(\bar{y})^{\gamma}\left\{\left(A\left(l^{F}+l^{M}\right)\right)^{1-\alpha-\gamma}\left(1-l^{M}\right)\right\}^{2}}
\end{aligned}
$$

Meanwhile, from (16), we have

$$
\frac{\partial p_{z}}{\partial l^{F}}=\frac{\partial p_{z}}{\partial l^{M}}=-\left(\frac{1-\alpha-\gamma}{\alpha}\right) \frac{\bar{x}}{A\left(l^{F}+l^{M}\right)^{2}}
$$

Hence, substituting from (A.1) (A.3) into the Euler equations of oil monopolists, $\left(\right.$ E. $\left.\mathrm{O}^{\mathrm{F}}\right)$ and $\left(\mathrm{E} . \mathrm{O}^{\mathrm{M}}\right)$, we get

$$
\begin{aligned}
& \left(\frac{1-\alpha-\gamma}{\alpha}\right) \frac{\bar{x}}{A\left(l^{F}+l^{M}\right)} A-\left(\frac{1-\alpha-\gamma}{\alpha}\right) \frac{\bar{x}}{A\left(l^{F}+l^{M}\right)^{2}} A l^{F} \\
& =w^{F}-\frac{\kappa\left(A\left(l^{F}+l^{M}\right)\right)^{-\alpha-\gamma}\left\{(1-\alpha-\gamma) A\left(1-l^{F}\right)-A\left(l^{F}+l^{M}\right)\right\}}{\alpha(\bar{x})^{\alpha-1}(\bar{y})^{\gamma}\left\{\left(A\left(l^{F}+l^{M}\right)\right)^{1-\alpha-\gamma}\left(1-l^{F}\right)\right\}^{2}} l^{F} \\
& =\frac{\kappa}{\alpha(\bar{x})^{\alpha-1}(\bar{y})^{\gamma}\left(A\left(l^{F}+l^{M}\right)\right)^{1-\alpha-\gamma}\left(1-l^{F}\right)} \\
& -\frac{\kappa\left(A\left(l^{F}+l^{M}\right)\right)^{-\alpha-\gamma}\left\{(1-\alpha-\gamma) A\left(1-l^{F}\right)-A\left(l^{F}+l^{M}\right)\right\}}{\alpha(\bar{x})^{\alpha-1}(\bar{y})^{\gamma}\left\{\left(A\left(l^{F}+l^{M}\right)\right)^{1-\alpha-\gamma}\left(1-l^{F}\right)\right\}^{2}} l^{F}
\end{aligned}
$$


and

$$
\begin{aligned}
& \left(\frac{1-\alpha-\gamma}{\alpha}\right) \frac{\bar{x}}{A\left(l^{F}+l^{M}\right)} A-\left(\frac{1-\alpha-\gamma}{\alpha}\right) \frac{\bar{x}}{A\left(l^{F}+l^{M}\right)^{2}} A l^{M} \\
& =w^{M}-\frac{\kappa\left(A\left(l^{F}+l^{M}\right)\right)^{-\alpha-\gamma}\left\{(1-\alpha-\gamma) A\left(1-l^{M}\right)-A\left(l^{F}+l^{M}\right)\right\}}{\alpha(\bar{x})^{\alpha-1}(\bar{y})^{\gamma}\left\{\left(A\left(l^{F}+l^{M}\right)\right)^{1-\alpha-\gamma}\left(1-l^{M}\right)\right\}^{2}} l^{M} \\
& =\frac{\kappa}{\alpha(\bar{x})^{\alpha-1}(\bar{y})^{\gamma}\left(A\left(l^{F}+l^{M}\right)\right)^{1-\alpha-\gamma}\left(1-l^{M}\right)} \\
& -\frac{\kappa\left(A\left(l^{F}+l^{M}\right)\right)^{-\alpha-\gamma}\left\{(1-\alpha-\gamma) A\left(1-l^{M}\right)-A\left(l^{F}+l^{M}\right)\right\}^{M}}{\alpha(\bar{x})^{\alpha-1}(\bar{y})^{\gamma}\left\{\left(A\left(l^{F}+l^{M}\right)\right)^{1-\alpha-\gamma}\left(1-l^{M}\right)\right\}^{2}}
\end{aligned}
$$

These are further simplified as follows.

$$
\begin{aligned}
& (1-\alpha-\gamma)(\bar{x})^{\alpha}(\bar{y})^{\gamma}\left(A\left(l^{F}+l^{M}\right)\right)^{1-\alpha-\gamma}\left(1-l^{F}\right)^{2} l^{M} \\
& =\kappa\left(l^{F}+l^{M}\right)^{2}-\kappa(1-\alpha-\gamma)\left(1-l^{F}\right)\left(l^{F}+l^{M}\right) l^{F}
\end{aligned}
$$

(Foreign agent's reaction function)

$$
\begin{aligned}
& (1-\alpha-\gamma)(\bar{x})^{\alpha}(\bar{y})^{\gamma}\left(A\left(l^{F}+l^{M}\right)\right)^{1-\alpha-\gamma}\left(1-l^{M}\right)^{2} l^{F} \\
& =\kappa\left(l^{F}+l^{M}\right)^{2}-\kappa(1-\alpha-\gamma)\left(1-l^{M}\right) l^{M}\left(l^{F}+l^{M}\right)
\end{aligned}
$$

(Middle agent's reaction function) 